\title{
Long-Term Potentiation of Synaptic Transmission in the Avian Hippocampus
}

\author{
Troy W. Margrie ${ }^{1}$, John A. P. Rostas, ${ }^{1}$ and Pankaj Sah ${ }^{2}$ \\ The Neuroscience Group and the ${ }^{1}$ Disciplines of Medical Biochemistry and ${ }^{2 H u m a n}$ Physiology, Faculty of Medicine and \\ Health Sciences, University of Newcastle, Callaghan NSW, 2308, Australia
}

\begin{abstract}
The avian hippocampus plays a pivotal role in memory required for spatial navigation and food storing. Here we have examined synaptic transmission and plasticity within the hippocampal formation of the domestic chicken using an in vitro slice preparation. With the use of sharp microelectrodes we have shown that excitatory synaptic inputs in this structure are glutamatergic and activate both NMDA- and AMPA-type receptors on the postsynaptic membrane. In response to tetanic stimulation, the EPSP displayed a robust long-term potentiation (LTP) lasting $>1 \mathrm{hr}$. This LTP was unaffected by blockade of NMDA receptors or chelation of postsynaptic calcium. Application of forskolin increased the EPSP and reduced paired-pulse facilitation
\end{abstract}

(PPF), indicating an increase in release probability. In contrast, LTP was not associated with a change in the PPF ratio. Induction of LTP did not occlude the effects of forskolin. Thus, in contrast to NMDA receptor-independent LTP in the mammalian brain, LTP in the chicken hippocampus is not attributable to a change in the probability of transmitter release and does not require activation of adenylyl cyclase. These findings indicate that a novel form of synaptic plasticity might underlie learning in the avian hippocampus.

Key words: calcium; plasticity; NMDA; memory; forskolin; PPF; cAMP
Activity-dependent changes in synaptic transmission are thought to be the cellular correlates of learning and memory in the CNS (Hebb, 1949; Squire, 1987). In the mammalian brain, the hippocampus plays a fundamental role in some forms of learning, and several forms of synaptic plasticity have been described at excitatory synapses within this structure (Malenka, 1994). The most intensively studied and best understood form of plasticity in the hippocampus is long-term potentiation (LTP), of which two distinct types exist at synapses in the mammalian hippocampus (Bliss and Collingridge, 1993; Nicoll and Malenka, 1995). The induction of LTP in area CA1 demonstrates a dependence on NMDA receptor activation and a subsequent rise in postsynaptic calcium. By contrast, LTP at the mossy fiber/CA3 synapse is attributable to activation of presynaptic adenylyl cyclase, and its induction is NMDA receptor independent (Nicoll and Malenka, 1995).

Neuroethological studies have shown that the avian hippocampus plays a pivotal role in particular types of learning (Sherry et al., 1992; Clayton and Krebs, 1995). The volume of the hippocampus is relatively larger in food-storing than in nonfood-storing birds (Krebs et al., 1989; Hampton et al., 1995), and the development of food storing is correlated with growth of the hippocampus (Barnea, 1994; Clayton, 1995). Retrieval of stored food is adversely affected by lesions of the hippocampus (Patel et al., 1997). Homing performance of pigeons is significantly reduced by hippocampal lesion (Bingman and Yates, 1992), as is their per-

Received Sept. 11, 1997; revised Nov. 20, 1997; accepted Nov. 21, 1997.

This work was supported by grants from the National Health and Medical Research Council of Australia (J.A.P.R., P.S.). P.S. is a Sylvia and Charles Viertel Senior Medical Research Fellow. We thank Robert Callister, Nishith Mahanty, and David Perkel for comments on this manuscript.

Correspondence should be addressed to Dr. Pankaj Sah, Neuroscience Group, Discipline of Human Physiology, Faculty of Medicine and Health Sciences, University of Newcastle, Callaghan, NSW 2308, Australia.

Copyright (C) 1998 Society for Neuroscience $0270-6474 / 98 / 181207-10 \$ 05.00 / 0$ formance on a sun compass-based spatial learning task (Bingman and Jones, 1994). In addition, the chicken hippocampus has also been implicated in recall of a passive avoidance task (Sandi et al., 1992). Thus, like its mammalian counterpart, the avian hippocampal formation is a key neuroanatomical structure involved in spatial and perhaps other types of memories.

Behavioral studies have suggested a functional similarity between the mammalian and avian hippocampus (Bingman et al., 1989; Krebs et al., 1989, and immunohistochemical studies reveal an abundance of homologous transmitters and related substances (Erichsen et al., 1991; Krebs et al., 1991; Veeman et al., 1994). However, some disagreement still remains concerning the degree of homology of the hippocampal formation between the two classes (Ramon y Cajal, 1911; Mollà et al., 1986). Because much about the physiology of synapses and the mechanisms underlying neuronal plasticity within this structure in the avian brain is still unknown (Wieraszko and Ball, 1993), an important question to ask is whether synapses within the avian hippocampus display forms of plasticity, such as LTP. In this study, using intracellular recording techniques in an in vitro slice preparation, we have investigated the mechanisms underlying LTP at synapses within the hippocampal formation of the adult domestic chicken.

\section{MATERIALS AND METHODS}

Preparation. Adult chickens (older than 10 weeks of age) were anesthetized with intraperitoneal pentobarbitone and decapitated, and the brain was removed rapidly and immersed in ice-cold Ringer's solution. All experimental procedures were in accordance with the guidelines of the University of Newcastle Animal Ethics and Care Committee. Coronal sections $400 \mu \mathrm{m}$ thick containing the hippocampus were cut on a vibratome [corresponding approximately to plates A 6.0 to A 8.6 of Kuenzel and Masson (1988)]. Slices were allowed to equilibrate in Ringer's solution at room temperature or $32^{\circ} \mathrm{C}$ for at least $1 \mathrm{hr}$, after which single slices were transferred to a recording chamber. Slices were immobilized with a flattened piece of platinum wire (outer diameter 0.5 $\mathrm{mm}$ ) across which stretched a "laddered" nylon stocking glued with 


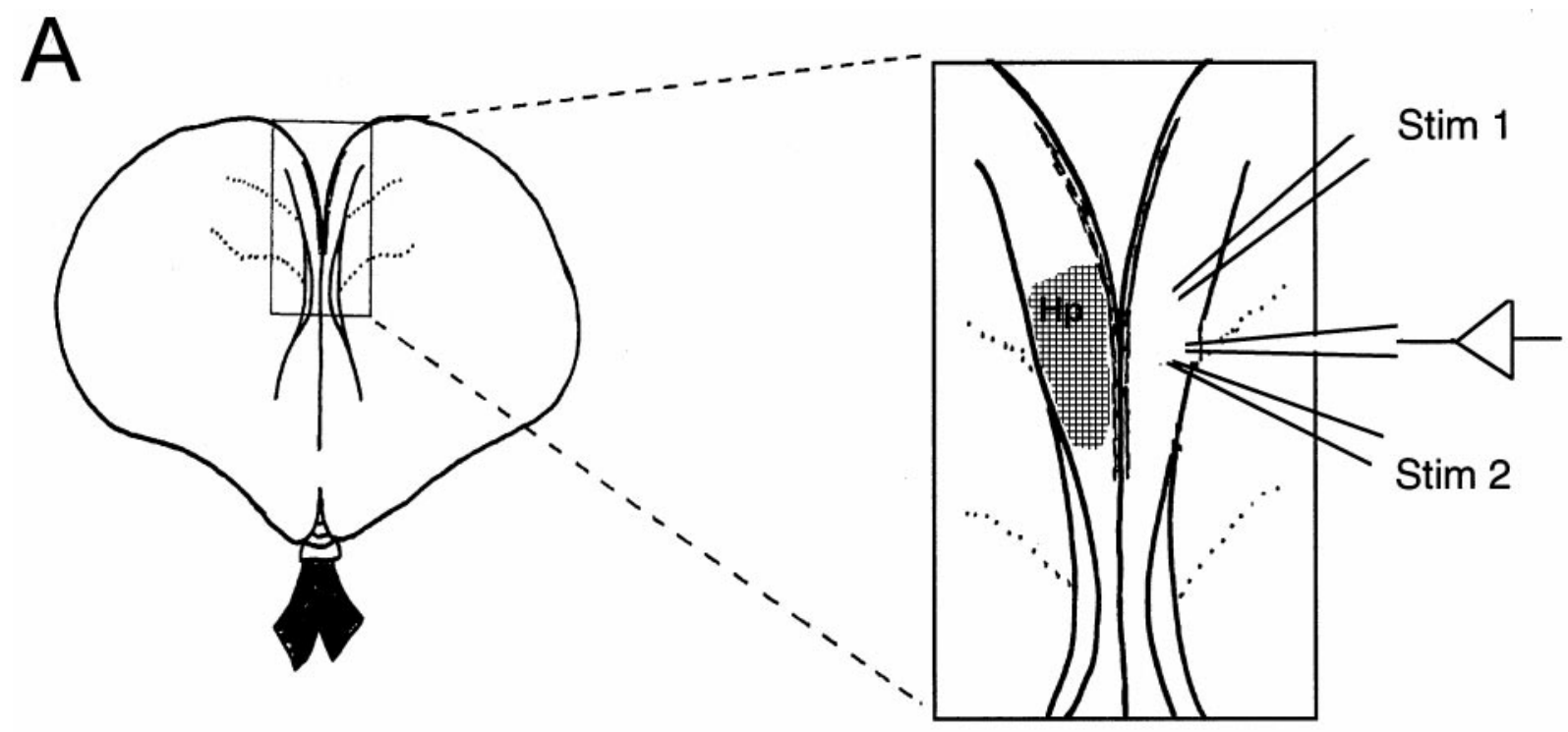

B

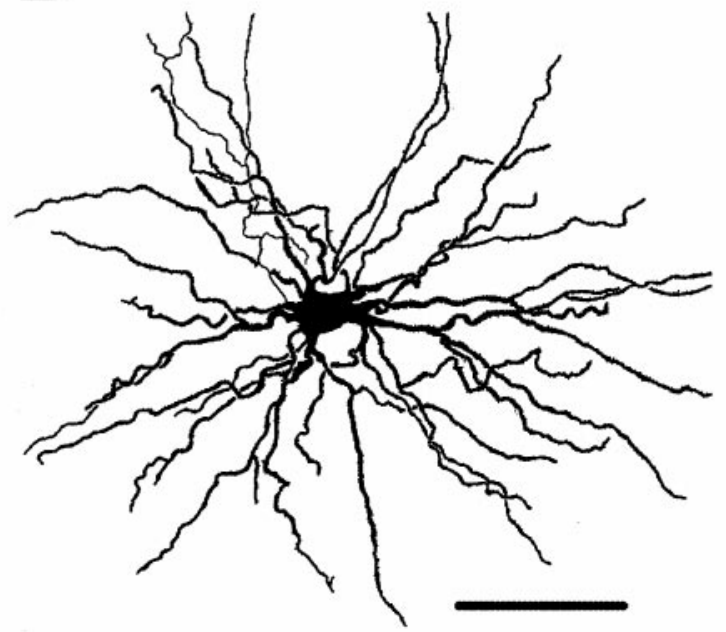

C

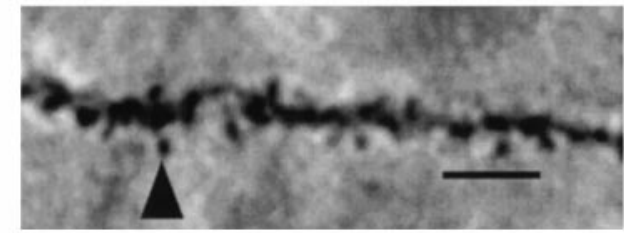

Figure 1. Tissue preparation and cell types in the chicken hippocampus. $A$, Schematic diagram of a coronal slice of chicken brain illustrating the location of the hippocampus and the position of stimulating and recording electrodes. Stimulating electrodes were placed superior (Stim 1) and inferior (Stim 2) to the recording electrode, which was placed in the middle third of the hippocampal formation. $B$, Camera lucida drawing of a typical spiny cell, from which recordings were made. Scale bar, $100 \mu \mathrm{m}$. $C$, High-power view of a dendritic segment from the cell illustrated in $B$. Note the dendritic spines that are evident along the entire length of dendrite. Scale bar, $10 \mu \mathrm{m}$.

cyanoacrylic glue. Slices were superfused with a Ringer's solution containing (in mM): $119 \mathrm{NaCl}, 2.5 \mathrm{KCl}, 1.3 \mathrm{MgCl}_{2}, 4.5 \mathrm{CaCl}_{2}, 1.0 \mathrm{Na}_{2} \mathrm{PO}_{4}$, $26.2 \mathrm{NaH}_{2} \mathrm{CO}_{3}, 10$ glucose, equilibrated with $95 \% \mathrm{O}_{2} / 5 \% \mathrm{CO}_{2}$ to maintain a $\mathrm{pH}$ of 7.4. The zero $\mathrm{Ca}^{2+}$ Ringer's solution contained no calcium, $200 \mu \mathrm{M}$ EGTA, and $6.5 \mathrm{mM} \mathrm{MgCl}_{2}$.

Electrophysiology. Intracellular recordings were made with sharp microelectrodes that had resistances of $50-120 \mathrm{M} \Omega$ when filled with 1 or 3 м KCl, $1 \mathrm{M} \mathrm{CsCl}$, or $1 \mathrm{M} \mathrm{KMeSO}_{4}, \mathrm{pH}$ 7.4. Microelectrodes were fabricated on a Flaming-Brown microelectrode puller (P-87). Signals were amplified using an Axoclamp2A amplifier (Axon Instruments, Foster City, CA), filtered at $1 \mathrm{kHz}$, and digitized at $5 \mathrm{kHz}$ using software (Neurosense) written under LabView for Windows (National Instruments). Input resistance was monitored continuously throughout each experiment. In experiments in which LTP was studied, electrodes were filled with $\mathrm{KCl}$ because they were found to be more stable. To measure the slope of the EPSP, two cursors were placed at the initial rising phase of the EPSP, and the slope between these two cursors was calculated. As with $\mathrm{KCl}$-filled electrodes, $\mathrm{GABA}_{\mathrm{A}}$-mediated inhibitory potentials were reversed, picrotoxin $(25 \mu \mathrm{M})$ was added to block them. When we tested for the presence of NMDA receptor-mediated EPSPs, electrodes were filled with $\mathrm{CsCl}$ to reduce outward currents and facilitate membrane depolarization. Only cells with membrane potentials more negative than $-50 \mathrm{mV}$ were included in this study. For loading cells with $1,2 \mathrm{bis}(\mathrm{o}-$ aminophenoxy)-ethane- $N, N, N^{\prime}, N^{\prime}$-tetra-acetic acid (BAPTA), electrode tips were filled with $200 \mathrm{~mm}$ BAPTA in $1 \mathrm{M} \mathrm{KCl}$ and $10 \mathrm{~mm}$ HEPES, pH 7.4, with $\mathrm{KOH}$. Bipolar, stainless steel stimulation electrodes (Fredrick Haer) were insulated except at their tips and placed superior and inferior to the recording electrode (see Fig. $1 A$ ). Afferent fibers were stimulated using a constant current stimulator (Axon Instruments). Stimuli typically were $0.5-2.0 \mathrm{~mA}$ and $20-40 \mu \mathrm{sec}$ in duration. For baseline measurements, afferent fibers were stimulated at $0.1 \mathrm{~Hz}$. LTP was generated by activating the fibers at $100 \mathrm{~Hz}$ for $1 \mathrm{sec}$, repeated twice with an interval 
A control

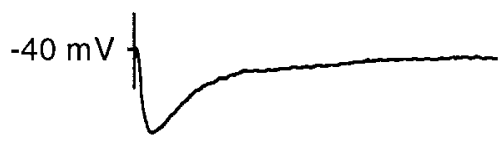

B control (bic)

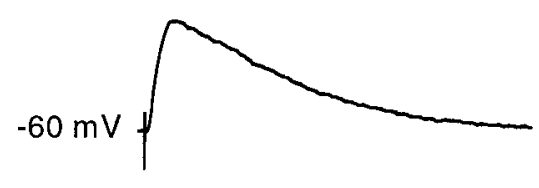

C control (CNQX, bic) bicuculline $(10 \mu \mathrm{M})$

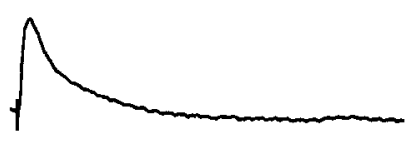

CNQX $(10 \mu \mathrm{M})$

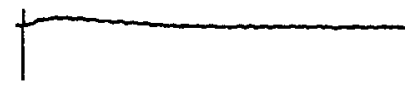

D-APV $(30 \mu M)$

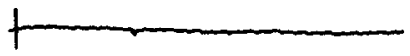

wash

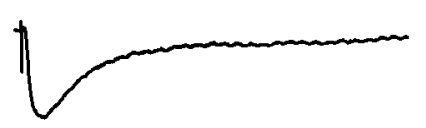

wash

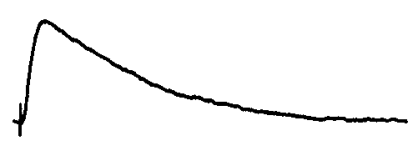

$100 \mathrm{~ms}$

$10 \mathrm{mV}$

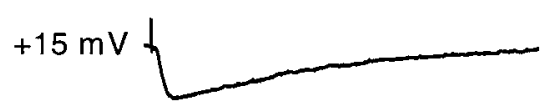

Figure 2. Synaptic transmission in the avian hippocampus. $A$ shows a typical response to synaptic stimulation in a cell in which the recording electrode contained $\mathrm{KMeSO}_{4}$. An EPSP is followed by a slower IPSP. Bath application of the $\mathrm{GABA}_{\mathrm{A}}$ receptor antagonist bicuculline (10 $\mu \mathrm{M}$ ) blocked the IPSP and revealed the EPSP; this effect was fully reversible after $30 \mathrm{~min}$ of washout. Resting membrane potential was $-70 \mathrm{mV}$, and the cell was depolarized to $-40 \mathrm{mV}$ by current injection to reveal the IPSP. $B$, When inhibitory transmission was blocked with bicuculline (10 $\mu \mathrm{M})$, stimulation of afferent fibers generated an EPSP that was reversibly abolished by the AMPA-kainate receptor antagonist CNQX (10 $\mu \mathrm{M})$. $C$, Depolarization of the cell in the presence of CNQX revealed a slower EPSP, which was blocked by the NMDA receptor antagonist D-APV (30 $\mu \mathrm{M})$. The NMDA receptor-mediated EPSP could be recovered after washout of APV. Note that the NMDA receptor-mediated EPSP is reversed because the cell was depolarized beyond the reversal potential for NMDA.

of $20 \mathrm{sec}$. Under control conditions, LTP was observed in 26 of 31 cells in which it was attempted (84\%). During 1 year of experiments, there was a period of 2 months during which LTP was seen in only 1 of 21 cells in which it was attempted. These cells have not been included in our analysis.

For intracellular staining, electrode tips were loaded with biocytin (4\% in $1 \mathrm{M} \mathrm{KCl}$ in $10 \mathrm{~mm}$ HEPES buffer, $\mathrm{pH}$ 7.4) by capillary action and then backfilled with $1 \mathrm{~m} \mathrm{KCl}$. All experiments were performed at room temperature. Sweep data shown are averages of 5-10 individual traces. All values are expressed as mean \pm SEM, and levels of statistical significance were determined by paired Student's $t$ test.

Drugs used were 6-cyano-7-nitroquinoxaline-2,3-dione (CNQX), bicuculline methiodide (Tocris Neuramin), 1,9-dideoxyforskolin, 2-amino-5phosphonovalerate (D-APV) (RBI Research Chemicals), forskolin, biocytin (Sigma), and BAPTA (Molecular Probes, Eugene, OR). Stock solutions of 1,9-dideoxyforskolin and forskolin were made up in dimethyl sulfoxide.

Histology. After the experiment, slices were fixed in $4 \%$ paraformaldehyde overnight. They were then permeabilized in $0.5 \%$ Triton X-100 and incubated overnight in avidin-horseradish peroxidase (ABC-Elite, Vectastain), washed again, and visualized using 3,3'-diaminobenzidine as a chromogen with nickel/cobalt intensification. Sections were then dehydrated in ethanol, cleared in xylene, and coverslipped. Labeled cells were visualized at a final magnification of $400 \times$ and reconstructed with the aid of a camera lucida drawing tube.

\section{RESULTS}

Intracellular recordings were made from neurons in the middle third of the hippocampus in coronal brain slices maintained in vitro (Fig. $1 A$, hatched region). We filled and recovered 22 neu- rons. Of these, 18 of 22 were spiny, long-axon multipolar neurons (Fig. $1 B, C$ ), three were short-axon multipolar neurons, and one was a horizontal neuron, according to the classification of Mollà et al. (1986). The average resting potential was $-59 \pm 1 \mathrm{mV}$ $(n=30)$.

\section{Characterization of synaptic inputs}

In cells impaled with electrodes filled with $\mathrm{KMeSO}_{4}$, electrical stimulation of nearby afferents evoked an EPSP, followed by an IPSP (Fig. 2A) $(n=8)$. IPSP was blocked completely and reversibly by application of bicuculline $(10 \mu \mathrm{M} ; n=7)($ Fig. $2 A)$ or picrotoxin $(25-100 \mu \mathrm{M} ; n=3)$, indicating that it was mediated by $\mathrm{GABA}_{\mathrm{A}}$ receptors. When inhibition was blocked, the EPSP was graded in amplitude and was blocked by application of calcium channel blockers, such as cadmium $(100 \mu \mathrm{M}$; $n=2)$ or nickel ( $1 \mathrm{~mm} ; n=3)$, or by the sodium channel blocker tetrodotoxin ( $1 \mu \mathrm{M} ; n=3)$, confirming that it was a synaptic potential. Application of the nonspecific glutamate antagonist kynurenic acid (1-2 mm; $n=4)$ or the AMPAkainate receptor antagonist CNQX $(10 \mu \mathrm{M} ; n=7)$ (Fig. $2 B)$ completely abolished the EPSP. Depolarization of the cell in the presence of CNQX revealed a slower EPSP, which was blocked by the NMDA receptor antagonist 2-amino-5phosphonovalerate D-APV (30 $\mu \mathrm{M} ; n=5)$ (Fig. 2C). All antagonists were fully effective within $10 \mathrm{~min}$ of application 

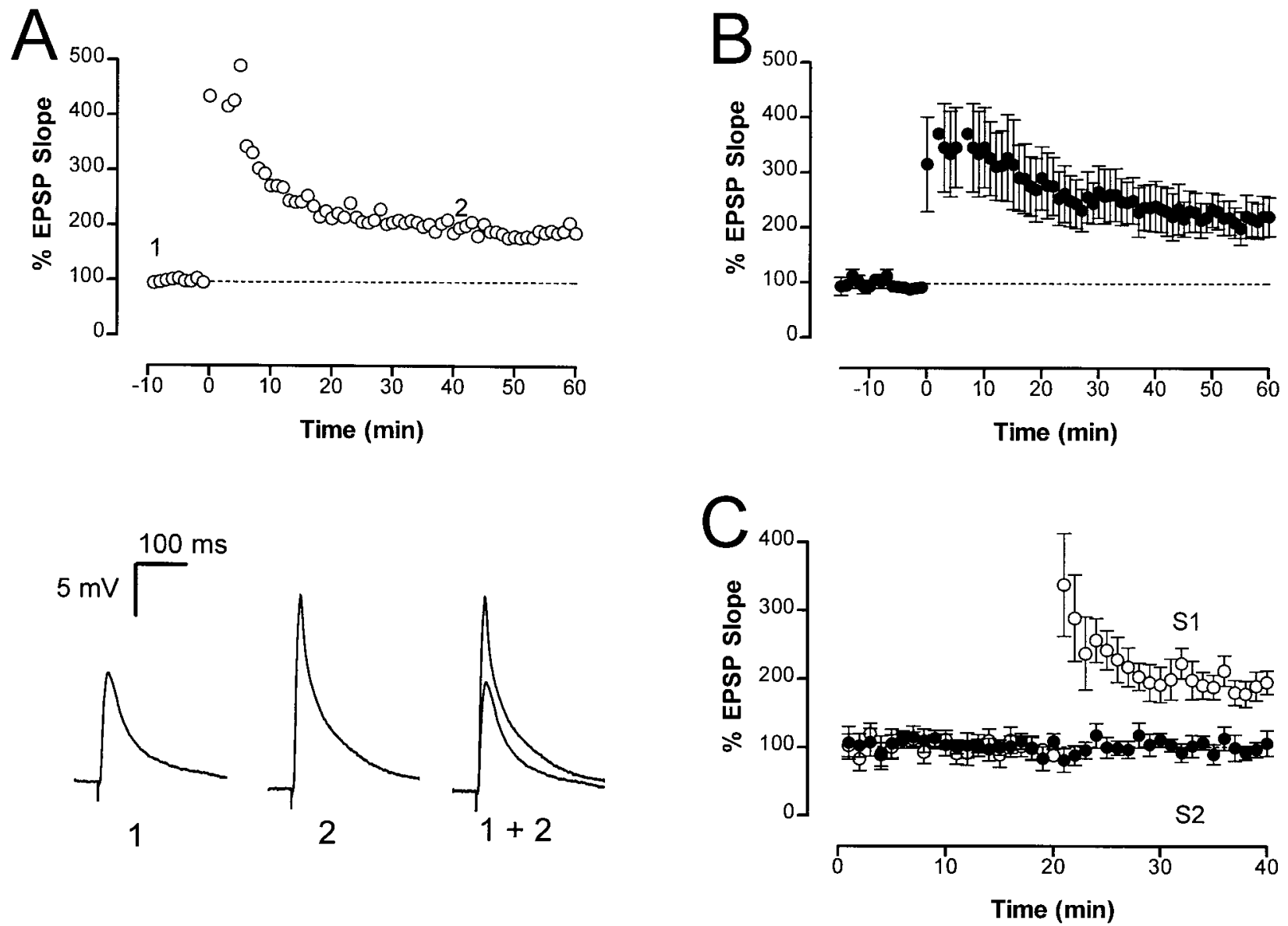

Figure 3. LTP in the chicken hippocampus. $A$, The normalized initial slope of the EPSP is plotted against time for one cell. Tetanic stimulation $(2 \times$ $100 \mathrm{~Hz}, 1 \mathrm{sec}$ ) was delivered at time 0 . Sweep data corresponding to the times shown in the top panel ( 1 and 2 ) are illustrated below. $B$, Group data from nine cells. Average LTP was $215 \pm 26 \%$ of baseline, 60 min after the tetanus. $C$, LTP is input specific. Shown is ensemble data $(n=6)$ in which two independent inputs ( $S 1$ and $S 2$ ) were alternately stimulated and a tetanus was delivered to $S 1$ at 20 min. $S 1$ showed a robust LTP, whereas $S 2$ was unaffected.

but were only slowly ( $>30 \mathrm{~min}$ ) reversible. These results show that the main excitatory transmitter at synapses in the avian hippocampus is glutamate and both AMPA and NMDA types of glutamate receptors are active in the postsynaptic membrane.

\section{LTP of synaptic transmission in the chicken hippocampus}

Tetanic stimulation of afferent fibers $(2 \times 100 \mathrm{~Hz}, 1 \mathrm{sec}$, separated by $20 \mathrm{sec}$ ) caused an immediate and long-lasting potentiation of the initial slope of the EPSP (Fig. $3 A$ ). This increase in the initial slope was maintained for the duration of the recording (up to $60 \mathrm{~min}$ ). The average potentiated response $60 \mathrm{~min}$ after tetanus was $215 \pm 26 \%(n=8)$ of the baseline response (Fig. $3 B)$ and was abolished by application of CNQX $(n=3)$, indicating that it was entirely attributable to an increase in glutamatergic transmission. To test whether the increase in synaptic strength was restricted to the stimulated synapses, two separate inputs were activated. The independence of the two inputs was tested by checking that the response to stimulation of the second input did not show facilitation when delivered shortly after stimulation of the first input. After obtaining a stable baseline at both inputs, a tetanus was delivered to one of the inputs. Only the input that was tetanized displayed LTP $(n=6)$ (Fig. $3 C$ ), showing that LTP is synapse specific (Andersen et al., 1977), as in the mammalian hippocampus.

Because both AMPA and NMDA receptors are active at these synapses, we next asked whether induction of LTP required the activation of NMDA receptors. Application of the NMDA receptor antagonist D-APV $(2 \times 25 \mu \mathrm{M}, 4 \times 50 \mu \mathrm{M}$, and $2 \times 100 \mu \mathrm{M}$ applied 20-50 min before tetanus) had no effect on the induction or maintenance of LTP (Fig. $4 A$ ). The average potentiated response in the presence of D-APV $30 \mathrm{~min}$ after tetanus $(236 \pm 49 \% ; n=8)$ was not significantly different $(p>0.05)$ from the values for untreated slices $(246 \pm 46 \%$; $n=8$ ) (Fig. $4 B$ ).

Although NMDA receptors are not involved in the induction of LTP, a rise in postsynaptic calcium may still be necessary. To test for a possible role of postsynaptic $\mathrm{Ca}^{2+}$ in the induction of LTP, we loaded the postsynaptic cell with the calcium chelator BAPTA for 20-40 min before delivery of the tetanus. The resting membrane potential in neurons loaded with BAPTA was $-62 \pm$ $4 \mathrm{mV}(n=7)$. We noted that action potentials were broader in the BAPTA-loaded neurons than in control cells (data not shown), confirming that BAPTA had diffused out of the microelectrode (Lancaster and Nicoll, 1987). Postsynaptic BAPTA failed to prevent induction of LTP (Fig. $5 A$ ). The average potentiated 


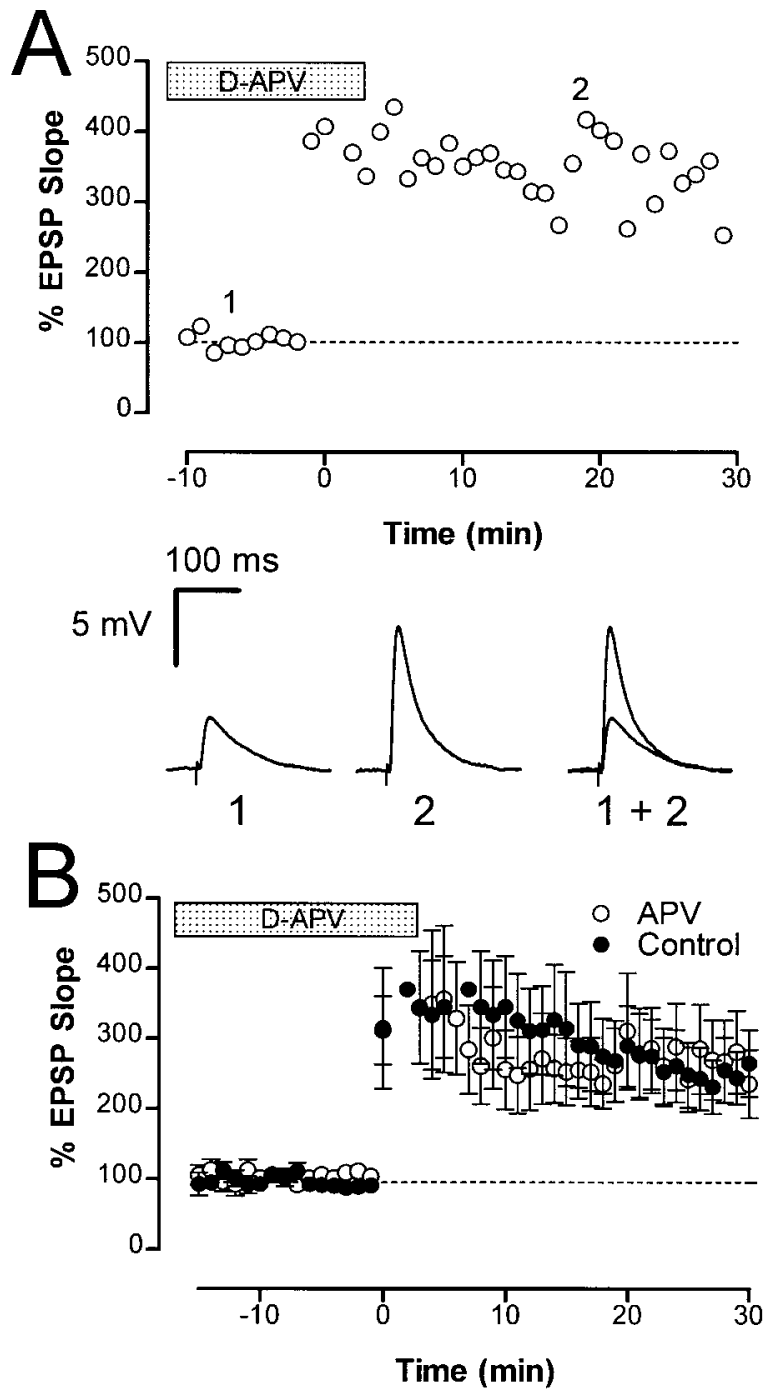

Figure 4. LTP does not require NMDA receptor activation. $A$, The normalized initial slope of the EPSP is plotted against time for a single cell that was superfused with $100 \mu \mathrm{M}$ D-APV for 40 min before delivery of a tetanus at time 0 . Sample traces taken at the times indicated ( 1 and 2 ) are shown below. $B$, Average LTP obtained in the presence of D-APV (open circles; $n=8$ ) was not different from that observed in control cells (filled circles). LTP measured at 30 min after tetanus was $236 \pm 49 \%$ and $245 \pm 37 \%$ in control cells and cells perfused with D-APV, respectively.

response in the BAPTA-loaded neurons $30 \mathrm{~min}$ after tetanus $(261 \pm 72 \% ; n=8)$ was not significantly different $(p>0.05)$ from controls (Fig. $5 B$ ). These results indicate that a rise in postsynaptic calcium is not important in triggering LTP at synapses in the chicken hippocampus.

\section{LTP requires $\mathrm{Ca}^{2+}$ entry into the presynaptic terminal}

Because LTP was not affected by postsynaptic injection of BAPTA, we next investigated whether calcium was required at all for LTP in the avian hippocampus. After a stable baseline was obtained, extracellular calcium was removed, leading to a rapid block of synaptic transmission (Fig. 6). An LTP-inducing stimulus was then delivered to the afferent fibers $(n=4)$. After extracellular calcium was restored to control levels, the EPSP was restored to its original amplitude, indicating that no LTP had been generated. A subsequent tetanus delivered in the presence of extracellular calcium was able to induce LTP. These data imply
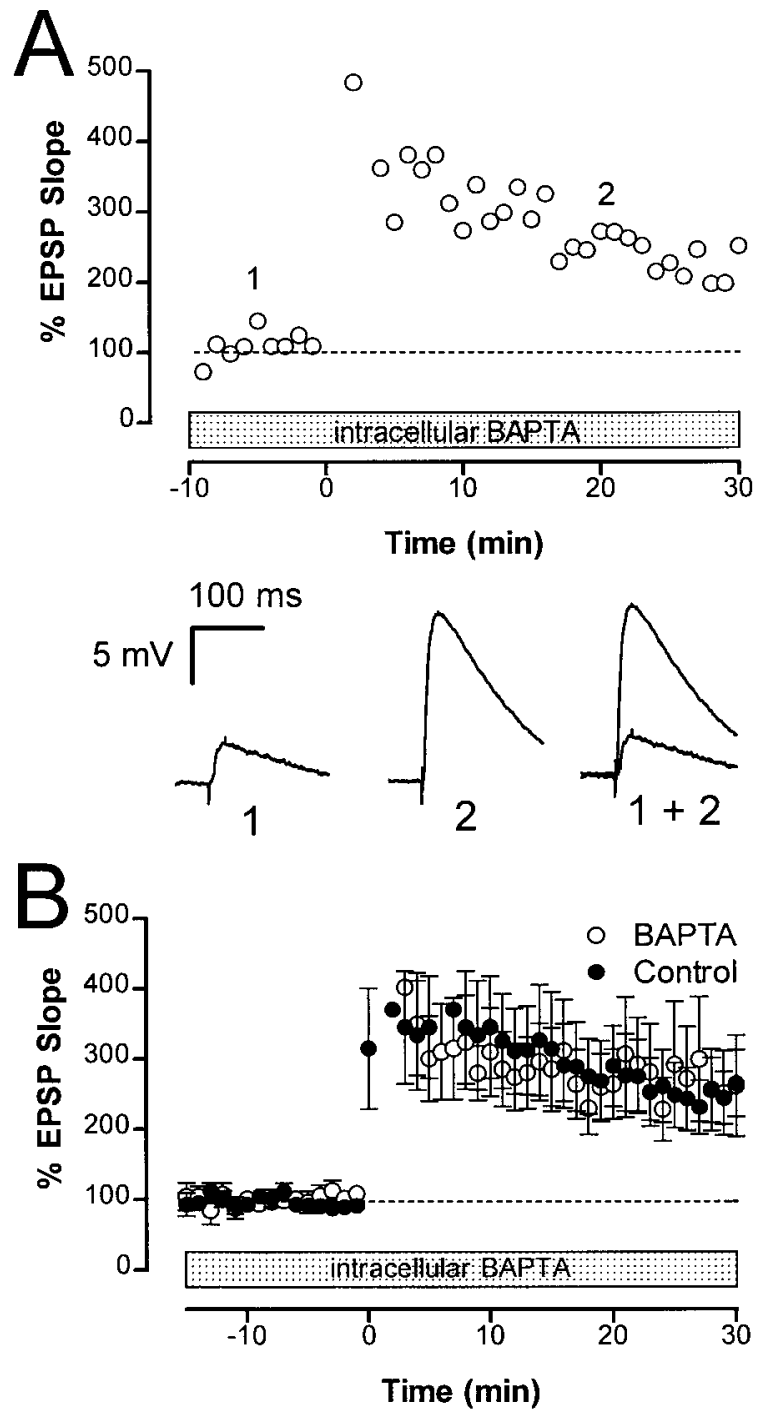

Figure 5. LTP does not require an increase in postsynaptic calcium. $A$, The normalized initial slope of the EPSP is plotted against time in a cell that was loaded with the calcium chelator BAPTA (200 mM in electrode) for $30 \mathrm{~min}$ before delivery of a tetanus at time 0 . Sample traces during the indicated times $(1$ and 2$)$ are shown below. $B$, Average potentiated response of BAPTA-loaded cells (open circles; $n=8$ ) was not significantly different from control cells ( filled circles; $n=8$ ). LTP measured at $30 \mathrm{~min}$ after tetanus was $261 \pm 72 \%$ and $245 \pm 37 \%$ in control cells and cells loaded with BAPTA, respectively.

that $\mathrm{Ca}^{2+}$ entry into the presynaptic terminal is essential for LTP induction.

\section{Activation of adenylyl cyclase potentiates synaptic transmission}

NMDA receptor-independent forms of synaptic plasticity have been described at a number of synapses in mammalian and invertebrate nervous systems (see Discussion). The one common feature of plasticity at these different synapses is activation of a presynaptic adenylyl cyclase, which leads to an increase in the probability of transmitter release. Therefore, we next examined whether activation of adenylyl cyclase might similarly potentiate synaptic transmission in the avian hippocampus.

Bath application of forskolin (1-25 $\mu \mathrm{M})$, an activator of adenylyl cyclase (Laurenza et al., 1989), induced a large potentiation of the EPSP (225 $\pm 46 \%, 50$ min after drug application; $n=5)$ (Fig. 

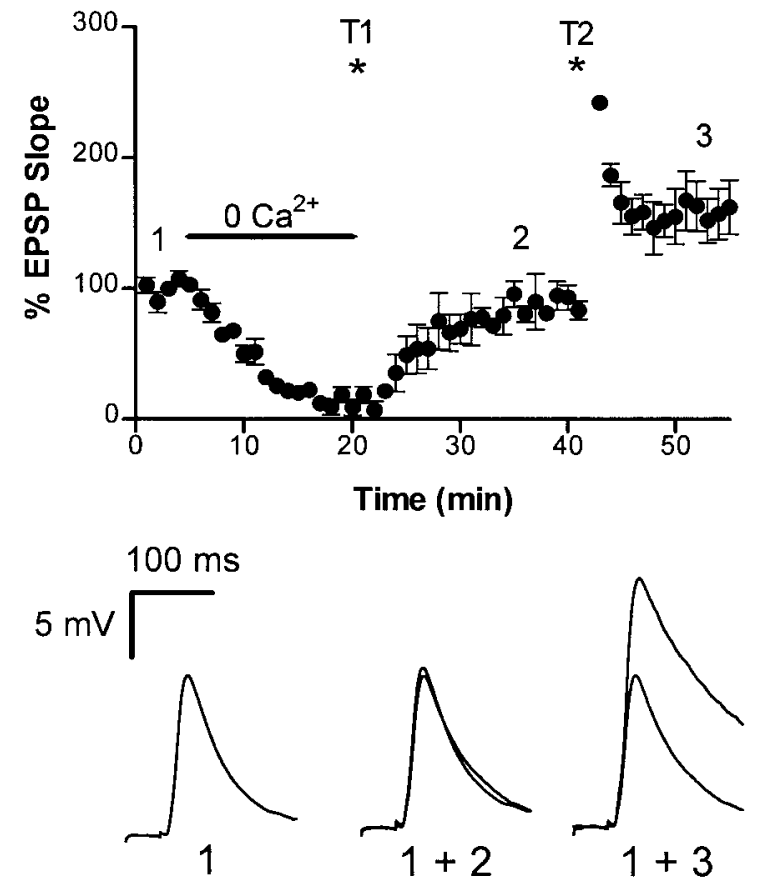

Figure 6. Extracellular calcium is necessary for LTP induction. The initial slope of the EPSP is plotted against time. At the time indicated, extracellular $\mathrm{Ca}^{2+}$ was removed from the perfusing Ringer's solution, leading to a rapid block of synaptic transmission. A tetanus $(2 \times 100 \mathrm{~Hz}$, $1 \mathrm{sec}$ ) was then delivered (T1). Reapplication of $\mathrm{Ca}^{2+}$ showed that LTP had not been induced. A second identical tetanus (T2) delivered in the presence of $\mathrm{Ca}^{2+}$ induced LTP $(n=4)$. Representative sweep data corresponding to before and after zero $\mathrm{Ca}^{2+}$ and after LTP induction are shown below.

$7 A$ ). To determine whether the forskolin-induced potentiation was caused by an increase in release probability, we tested for a change in paired-pulse facilitation (PPF). When a synapse is stimulated twice with a short interpulse interval, the ratio of the response to the second stimulus to that of the first is called the PPF ratio. Manipulations that increase the probability of transmitter release reduce the PPF ratio (Katz and Miledi, 1968; Zucker, 1989; Manabe et al., 1993; Isaacson and Walmsley, 1995). Paired pulses were applied at an interval of $175 \mathrm{msec}$. The increase in the EPSP after forskolin application was associated with a clear decrease in the PPF ratio (normalized PPF ratio decreased to $0.65 \pm 0.03 ; p<0.001 ; n=5$ ) (Fig. $7 B$ ), consistent with a presynaptic action of forskolin. The inactive isomer of forskolin, 1,9-dideoxyforskolin, which mimics many of the nonspecific effects of forskolin, but does not activate adenylyl cyclase (Laurenza et al., 1989), had no effect on the EPSP when applied at a concentration of $25-50 \mu \mathrm{M}(n=3)$ (Fig. 7C). This result is consistent with forskolin acting through the cAMP pathway to potentiate synaptic transmission via a presynaptic mechanism.

\section{LTP is not associated with a change in PPF}

If tetanic stimulation recruits the same biochemical pathways as those activated by forskolin, we would expect LTP to also be associated with a reduction in the PPF ratio (Zalutsky and Nicoll, 1990; Weisskopf et al., 1994). The results from seven cells in which we simultaneously measured LTP and the PPF ratio are shown in Figure 8. After an LTP inducing tetanus, the PPF ratio decreased during post-tetanic potentiation, as expected (Zucker, 1989), but then returned to baseline levels. The PPF ratio mea-
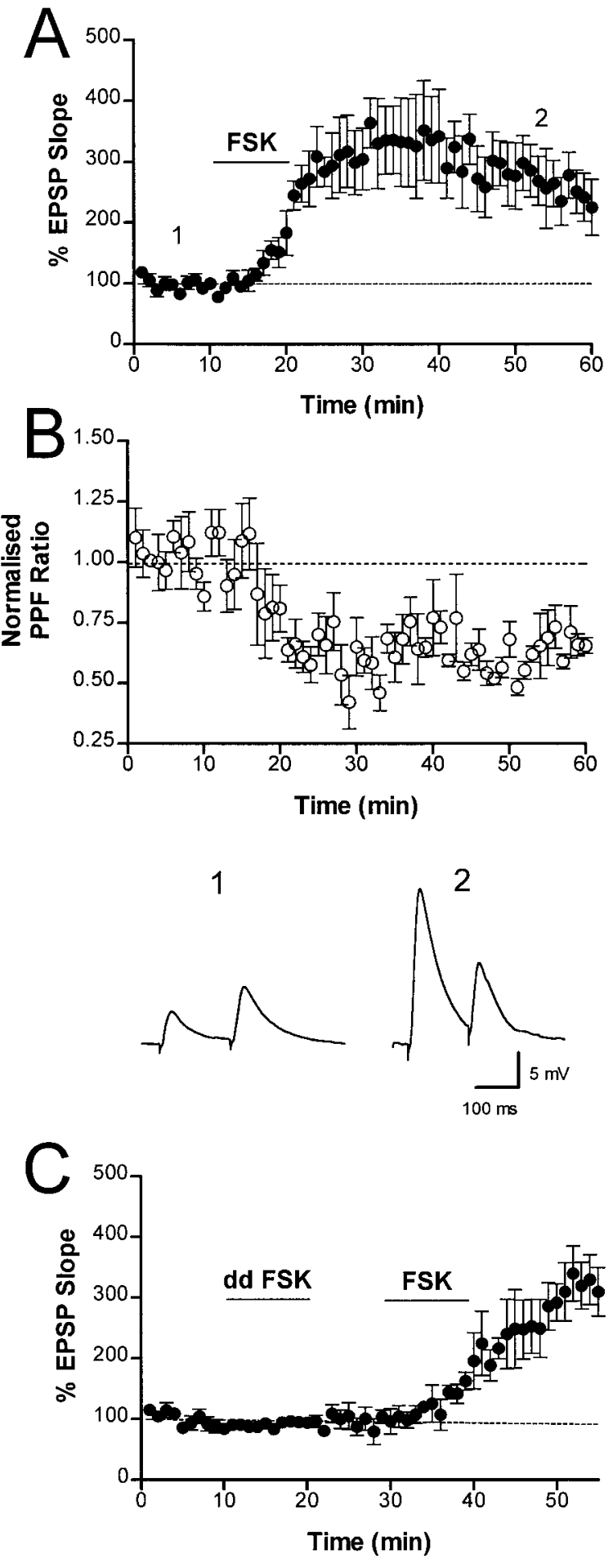

Figure 7. Application of forskolin potentiates synaptic transmission by a presynaptic mechanism. $A$, The normalized initial slope of the EPSP $(n=$ 5 ) is plotted against time. After a stable baseline was obtained, a $10 \mathrm{~min}$ application of forskolin $(F S K)(1-25 \mu \mathrm{M})$ at the times indicated by the bar produced a large sustained increase $(225 \pm 46 \%)$ in the EPSP slope. $B$, The PPF ratio was significantly reduced during the forskolin-induced potentiation. Synapses were stimulated twice, with an interpulse interval of $175 \mathrm{msec}$. The ratio of the slope of the second EPSP to that of the first (the PPF ratio) has been normalized and plotted. Average traces taken at the times indicated in $A$ are shown below. $C$, Di-deoxyforskolin ( $d d F S K$ ) $(25-50 \mu \mathrm{M})$ applied for $10 \mathrm{~min}$ during the period indicated by the bar had no effect on the EPSP. A subsequent application of FSK produced a robust potentiation $(n=3)$. 

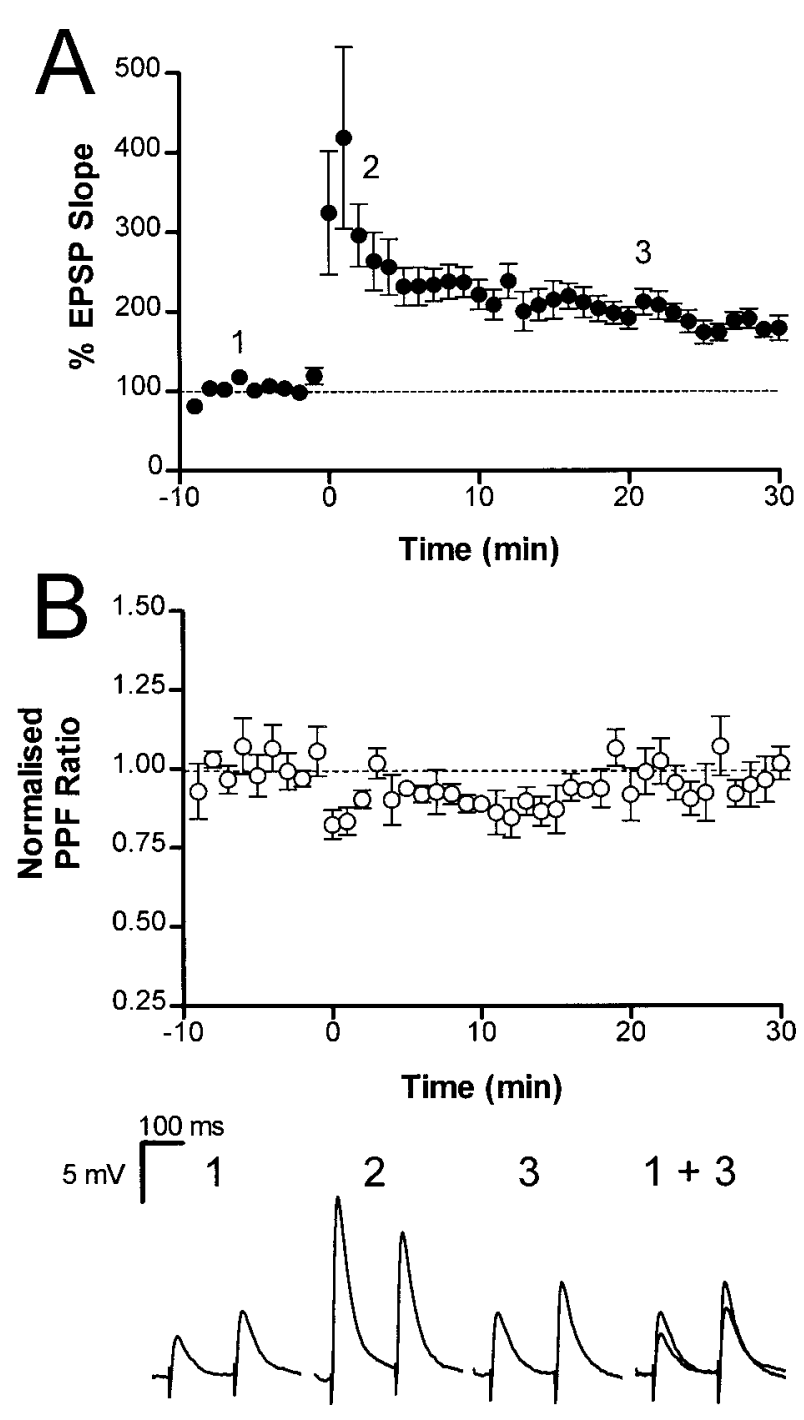

Figure 8. Long-term potentiation is not associated with a change in paired pulse facilitation. The average normalized initial slope of the EPSP is plotted against time for seven cells. The normalized PPF ratio is plotted in $B$. Tetanic stimulation $(2 \times 100 \mathrm{~Hz}, 1 \mathrm{sec})$ was delivered at time 0 . After the tetanus the PPF ratio was transiently reduced during post-tetanic potentiation but then returned to baseline levels. Average traces taken at the times indicated in $A$ are shown at the bottom.

sured during LTP $(0.98 \pm 0.04$, taken at $20 \mathrm{~min})$ was not significantly different $(p>0.05)$ from that measured during the baseline period (Fig. $8 B$ ). This result indicates that LTP in the chicken hippocampus is unlikely to result from a change in release probability. However, it remains possible that because the absolute enhancement of the EPSP by forskolin was larger than that associated with LTP, we were unable to detect a small change in the PPF during LTP, when the increment in release probability was less.

To examine this question, we manipulated release probability by altering the extracellular $\mathrm{Ca}^{2+} / \mathrm{Mg}^{2+}$ ratio (Katz and Miledi, 1968; Manabe et al., 1993) to increase the EPSP to a similar level as that observed during LTP (Fig. $9 A$ ). Changing the $\mathrm{Ca}^{2+} / \mathrm{Mg}^{2+}$ ratio from $0.5 \mathrm{Ca}^{2+} / 6 \mathrm{Mg}^{2+}$ to $2.5 \mathrm{Ca}^{2+} / 4 \mathrm{Mg}^{2+}$ increased the initial slope of the EPSP by $236 \pm 9 \%$ (Fig. $9 B_{1}$ ) and was associated with a clear decrease in the PPF ratio $(0.69 \pm .05 ; n=$ 4) (Fig. $9 B_{2}$ ). This result demonstrates that if the PPF ratio had changed during LTP we would have detected it. Thus, forskolin and tetanic stimulation must engage distinct second messenger cascades with different final targets. Consistent with this idea, previous induction of LTP had no effect on the potentiation produced by forskolin (Fig. 9C).

\section{DISCUSSION}

In this study we have examined some properties of excitatory synaptic transmission in the chicken hippocampus. Our results show that although transmission in this structure shares many features with those in its mammalian counterpart, there are also some distinct differences.

At least six different cell types have been identified within the chicken hippocampus by Golgi staining techniques (Ramon y Cajal, 1911; Mollà et al., 1986). The large, spiny neurons filled with biocytin and recovered in this study are likely to be the long-axon, spiny cells described by Mollà et al. (1986). Afferent fibers, which are a mixture of cortical afferents and local axons, course through the hippocampal formation. Stimulation of these fibers evoked a glutamatergic EPSP followed by a GABAergic

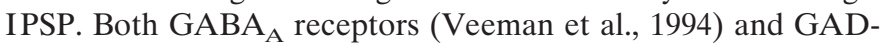
immunoreactive fibers (Krebs et al., 1991) have been demonstrated in the avian hippocampus, suggesting that local circuitry similar to that seen in the mammalian hippocampus (e.g., Buhl et al., 1994) may also be present in the avian homolog.

Stimulation of afferent fibers activated both AMPA-kainate and NMDA receptors in the postsynaptic membrane. These receptors are thought to be colocalized in the postsynaptic membrane in the mammalian hippocampus (Bekkers and Stevens, 1989). It will be of interest to see whether a similar situation holds in the avian system. Tetanic stimulation of excitatory inputs led to an immediate and sustained enhancement of the EPSP. This LTP was homosynaptic, and its induction was not dependent on activation of NMDA receptors. In support of this, a previous study utilizing field recordings in the pigeon hippocampus also reported that LTP was not blocked by the NMDA receptor antagonist D-APV (Wieraszko and Ball, 1991). In our study, injection of the calcium chelator BAPTA into the postsynaptic cell also failed to prevent the induction of LTP, indicating that a rise in postsynaptic calcium may also be unnecessary for LTP induction. As in other studies examining the role of postsynaptic calcium (e.g., Lynch et al., 1983), we loaded BAPTA via sharp microelectrodes. Because action potentials in BAPTA-loaded cells were broader, we are confident that BAPTA had reached regions of the cell involved in spike generation; however, we cannot be certain of the concentration of BAPTA reached at the subsynaptic membrane. If postsynaptic calcium was not buffered effectively, then it remains possible that the induction of LTP may require influx of calcium into the postsynaptic cell.

In the mammalian hippocampus, two distinct types of LTP have been described (Bliss and Collingridge, 1993; Nicoll and Malenka, 1995). One form, best studied at synapses made by the Schaffer collaterals onto CA1 pyramidal neurons, requires the activation of postsynaptic NMDA receptors. The subsequent rise in postsynaptic calcium is necessary for the induction of LTP at these synapses. The locus of expression of this form of LTP is not yet resolved, but both presynaptic and postsynaptic mechanisms have been implicated ((Bliss and Collingridge, 1993; Nicoll and Malenka, 1994). A second type of LTP is present at synapses made by the mossy fibers onto CA3 pyramidal neurons (Harris and Cotman, 1986; Zalutsky and Nicoll, 1990). Induction of LTP at these synapses does not require NMDA receptor activation or 


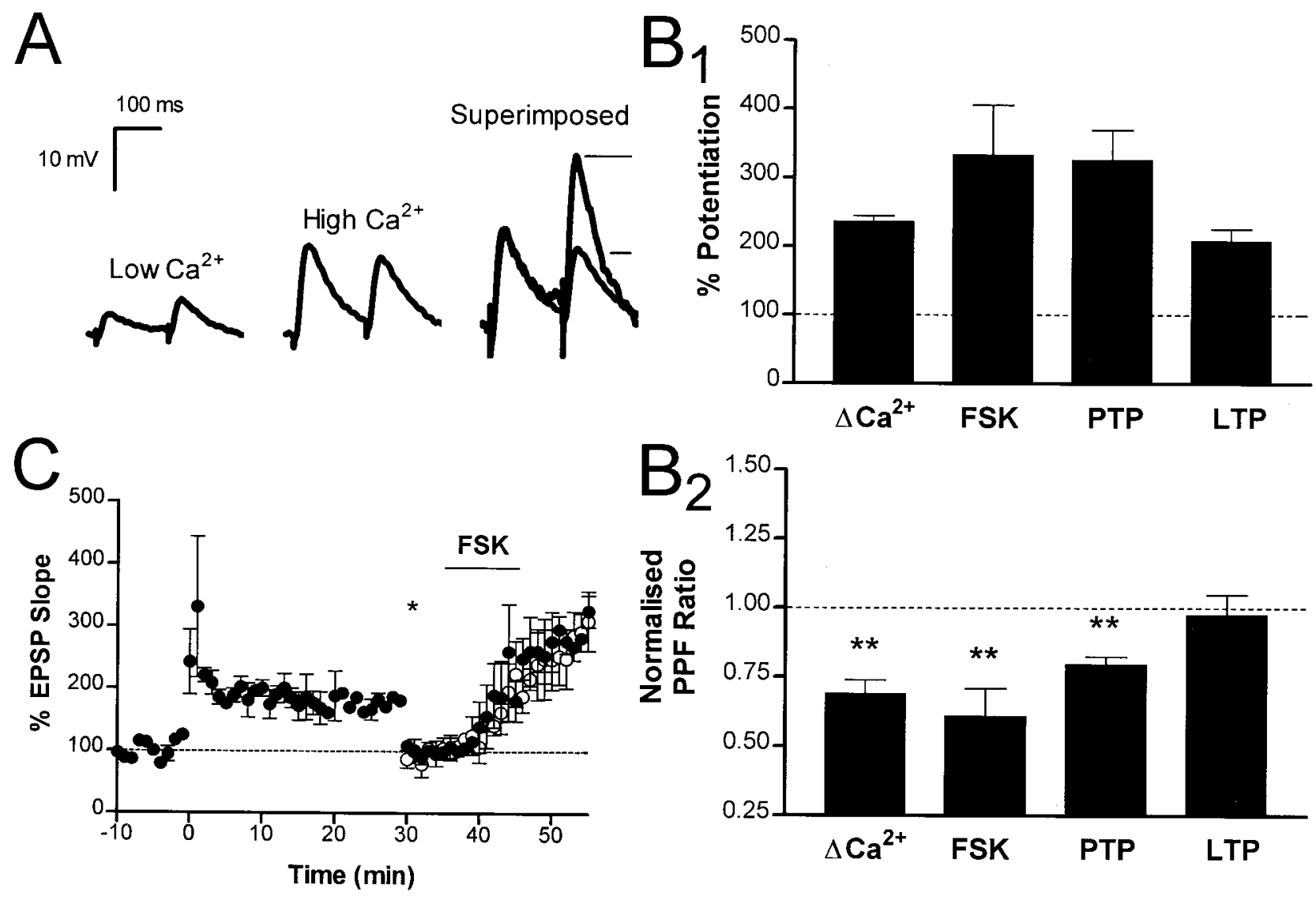

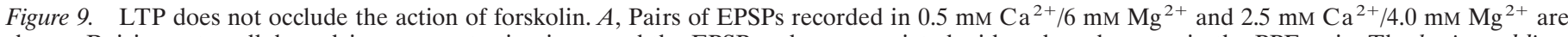

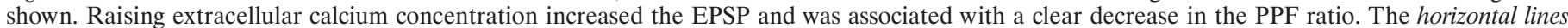

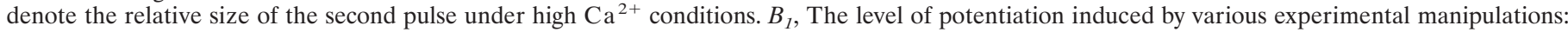

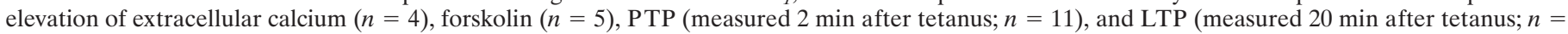

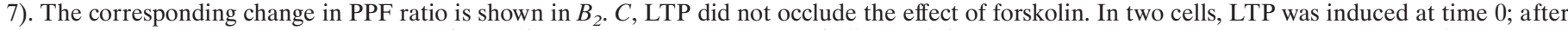

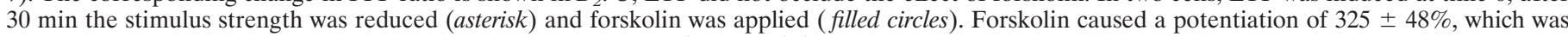

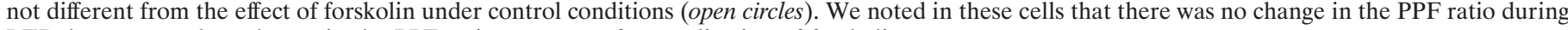
LTP; however, a clear change in the PPF ratio was seen after application of forskolin.

a change in postsynaptic calcium; both the induction and expression of this form of LTP appear to be presynaptic (Zalutsky and Nicoll, 1990; Huang et al., 1994; Weisskopf et al., 1994).

Synaptic plasticity that is independent of NMDA receptors and postsynaptic calcium has also been described at synapses in the mammalian cerebellum (Salin et al., 1996) and autonomic nervous system (Briggs and McAfee,1988), at the crustacean neuromuscular junction (Wojtowicz and Atwood, 1988; Dixon and Atwood, 1989), and in the abdominal ganglion of Aplysia (Goelet et al., 1986). The one common feature of plasticity at these different synapses is an essential role for adenylyl cyclase: in each case, activation of presynaptic adenylyl cyclase leads to an increase in the probability of transmitter release.

In the chicken hippocampus, application of forskolin, an activator of adenylyl cyclase, potentiated excitatory synaptic transmission. As shown at other synapses (e.g., Weisskopf et al., 1994), this increase in the EPSP was attributable to a presynaptic action because it was associated with a clear decrease in the PPF ratio. In contrast, LTP was not associated with a change in PPF and did not occlude the effect of forskolin. These results indicate that the increase in the EPSP during LTP is unlikely to be caused by a change in the probability of transmitter release. Furthermore, LTP in this system is unlikely to engage the cAMP pathway. It should be noted, however, that the locus of LTP could still be presynaptic, resulting for example from an increase in the number of release sites or a change in the amount of transmitter released per vesicle.

What then is the trigger for LTP in the avian hippocampus? Our data do not allow us to determine whether the induction of LTP resides in the pre- or postsynaptic cell. Although changes in postsynaptic calcium do not appear to be important, calcium entry into the presynaptic terminal(s) was necessary for the induction of LTP. This calcium entry may simply be necessary for transmitter release, or it may itself provide the trigger for LTP, as at mossy fiber terminals in the mammalian system. Several proteins present in the presynaptic terminal are potential targets for calcium. Among the most abundant of these is calcium/calmodulindependent protein kinase II (CaMPK-II). It has been suggested that activation of CaMPK-II regulates potentiation in a stimulus frequency-dependent manner at the MF/CA3 synapse (Salin et al., 1996). CaMPK-II is also present in presynaptic terminals in the avian forebrain (Weinberger and Rostas, 1988), raising the possibility that this may be a target for calcium during tetanic stimulation. It should be noted, however, that because we have introduced BAPTA via a sharp microelectrode, if the BAPTA concentration in the postsynaptic cell was ineffective in com- 
pletely buffering postsynaptic calcium, then the blockade of LTP in low calcium could be interpreted as being caused by a reduction of calcium influx into the postsynaptic cell.

On the basis of results from behavioral studies, and the similarity in neurotransmitter and peptides in the two structures, a functional similarity has been suggested between the mammalian and avian hippocampus. The mammalian hippocampus has well defined anatomical landmarks, and cell layers are clearly seen in slices. No cell layers were evident in slices of chicken hippocampus; the area that we have recorded from has been suggested to be homologous to the dentate gyrus of the mammalian hippocampus (Showers, 1982; Erichsen et al., 1991). In the cell layer of the dentate gyrus in mammals, neurons are spiny, with a somewhat sparse apical dendritic tree but few or no basal dendrites (Claiborne et al., 1990). In contrast, the cells we have recorded from are spiny, with rather symmetrical, bushy dendritic trees (as seen in coronal sections) (Fig. 1). Our observation that glutamatergic afferents activate both NMDA and non-NMDA receptors is similar to observations of synapses in the dentate gyrus (Colino and Malenka, 1993); however, NMDA receptor-independent LTP has been demonstrated primarily at synapses between the mossy fibers and CA3 pyramidal neurons in the mammalian hippocampus (Nicoll and Malenka, 1995). Although Timms stain does suggest the presence of heavy metals in the chicken hippocampus (Faber et al., 1989), the presence of a fiber system similar to the mossy fibers in the avian hippocampus has been disputed (Erichsen et al., 1991). Taken together, these results point to similarities and differences between the mammalian and avian equivalents. Our physiological data indicate that the glutamatergic synapses in the region we are recording from share features with neurons in the mammalian dentate as well as regions CA1 and CA3. Clear demarcation of anatomical boundaries similar to that seen in the mammalian hippocampus remains to be determined.

Lesions of the hippocampus in birds have shown that various learning tasks are dependent on this structure (Clayton and Krebs, 1995). In the mammalian hippocampus, in which NMDA receptor-dependent LTP is predominant, disruption of NMDA receptors by pharmacological or genetic interventions blocks behavioral tasks thought to involve LTP (Tonegawa, 1995). In the avian system, we have shown that LTP does not require activation of NMDA receptors. It will be interesting, therefore, to examine the role of hippocampal NMDA receptor function in spatial learning in birds.

In conclusion, we have shown that the synapses in the chicken hippocampus, like their mammalian counterparts, display LTP. This LTP does not require activation of NMDA receptors, is independent of adenylyl cyclase, and is not associated with a reduction in PPF. These findings indicate that a novel form of synaptic plasticity may underlie learning in the avian hippocampus.

\section{REFERENCES}

Andersen P, Sundberg SH, Sveen SH, Wigstrom H (1977) Specific longlasting potentiation of synaptic transmission in hippocampal slices. Nature 266:736-737.

Barnea A, Nottebohm F (1994) Seasonal recruitment of hippocampal neurons in adult free-ranging black-capped chickadees. Proc Natl Acad Sci USA 91:11217-11221.

Bingman VP, Jones T (1994) Sun-compass-base spatial learning impaired in homing pigeons with hippocampal lesions. J Neurosci 14:6687-6694.

Bingman VP, Yates G (1992) Hippocampal lesions impair navigational learning in experienced homing pigeons. Behav Neurosci 106:229-232.
Bingman VP, Bagnoli P, Ioalé P, Casini G (1989) Behavioral and anatomical studies of the avian hippocampus. In: The hippocampus, new vistas (Chan-Palay V, Koehler C, eds), pp 379-394. New York: Liss.

Bekkers JM, Stevens CF (1989) NMDA and non-NMDA receptors are co-localised at individual excitatory synapses in cultured rat hippocampus. Nature 341:230-233.

Bliss TVP, Collingridge GL (1993) A synaptic model of memory: long term potentiation in the hippocampus. Nature 361:31-39.

Briggs CA, McAfee DA (1988) Long-term potentiation at nicotinic synapses in the rat superior cervical ganglion. J Physiol (Lond) 404:129-144.

Buhl EH, Halasy K, Somogyi P (1994) Diverse sources of hippocampal unitary inhibitory postsynaptic potentials and the number of synaptic release sites. Nature 368:823-828.

Claiborne BJ, Amaral DG, Cowan WM (1990) Quantitative, threedimensional analysis of granule cell dendrites in the rat dentate gyrus. J Comp Neurol 302:206-219.

Clayton NS (1995) Development of memory and the hippocampus: comparison of food-storing and nonstoring birds on a one-trial associative memory task. J Neurosci 15:2796-2807.

Clayton NS, Krebs JR (1995) Memory in food storing birds: from brain to behaviour. Curr Opin Neurobiol 5:149-154.

Colino A, Malenka RC (1993) Mechanisms underlying induction of long-term potentiation in the rat medial and lateral perforant paths in vitro. J Neurophysiol 69:1150-1159.

Dixon D, Atwood H (1989) Adenylate cyclase is essential for long-term facilitation at the crayfish neuromuscular junction. J Neurosci 9:4246-4252.

Erichsen JT, Bingman VP, Krebs JR (1991) The distribution of neuropeptides in the dorsomedial telencephalon of the pigeon (Columbia livia): a basis for regional subdivisions. J Comp Neurol 314:478-492.

Faber H, Braun K, Zuschratter W, Scheich H (1989) System-specific distribution of zinc in the chick brain. A light- and electron-microscopic study using the Timm method. Cell Tissue Res 258:247-257.

Goelet P, Castellucci VF, Schacher S, Kandel ER (1986) The long and the short of long-term memory: a molecular framework. Nature 322:419-422.

Hampton RR, Sherry DF, Shettleworth SJ, Khurgel M, Ivy G (1995) Hippocampal volume and food-storing behaviour are related in parids. Brain Behav Evol 45:54-61.

Harris EW, Cotman CW (1986) Long-term potentiation of guinea-pig mossy fiber responses is not blocked by $N$-methyl D-aspartate antagonists. Neurosci Lett 70:132-137.

Hebb DO (1949) The organization of behaviour. New York: Wiley.

Huang YY, Xiao-Ching L, Kandel ER (1994) cAMP contributes to mossy fibre LTP by initiating both a covalently mediated early phase and macromolecular synthesis-dependent late phase. Cell 79:69-79.

Isaacson JS, Walmsley B (1995) Counting Quanta: direct measurements of transmitter release at a central synapse. Neuron 15:875-884.

Katz B, Miledi R (1968) The role of calcium in neuromuscular facilitation. J Physiol (Lond) 195:481-492.

Krebs JR, Sherry DF, Healy SD, Perry VH, Vaccarino AL (1989) Hippocampal specialisation of food-storing birds. Proc Natl Acad Sci USA 88:1388-1392.

Krebs JR, Erichsen JT, Bingman VP (1991) The distribution of neurotransmitters and neurotransmitter related enzymes in the dorsomedial telencephalon of the pigeon (Columbia livia). J Comp Neurol 314:467-477.

Kuenzel J, Masson MA (1988) A stereotaxic atlas of the brain of the chick (Gallus domesticus). Baltimore, MD: Johns Hopkins UP.

Lancaster B, Nicoll RA (1987) Properties of two calcium-activated hyperpolarizations in rat hippocampal neurones. J Physiol (Lond) 389:187-204.

Laurenza A, Sutkowski EM, Seamon KB (1989) Forskolin: a specific stimulator of adenylyl cyclase or a diterpene with multiple sites of action? Trends Pharmacol 10:442-447.

Lynch G, Larson J, Kelso S, Barrionuevo G, Schottler F (1983) Intracellular injections of EGTA block induction of hippocampal long-term potentiation. Nature 305:719-721.

Malenka RC (1994) Synaptic plasticity in the hippocampus: LTP and LTD. Cell 78:535-538.

Manabe T, Wyllie DJA, Perkel DJ, Nicoll RA (1993) Modulation of synaptic transmission and long-term potentiation: effects on paired 
pulse facilitation and EPSC variance in the CA1 region of the hippocampus. J Neurophysiol 70:145-149.

Mollà R, Rodriguez J, Calvet S, Garcia-Verdugo JM (1986) Neuronal types of the cerebral cortex of the adult chicken (Gallus gallus). J Hirnforschung 27:381-390.

Nicoll RA, Malenka RC (1995) Contrasting properties of two forms of long term potentiation in the hippocampus. Nature 377:115-118.

Patel SN, Clayton NS, Krebs JR (1997) Hippocampal tissue transplants reverse lesion-induced spatial memory deficits in Zebra finches (Taeniopygia guttata). J Neurosci 17:3861-3869.

Ramon y Cajal S (1911) Histology of the nervous system of man and vertebrates. New York: Oxford UP.

Salin PA, Scanziani M, Malenka RC, Nicoll RA (1996) Distinct shortterm plasticity at two excitatory synapses in the hippocampus. Proc Natl Acad Sci USA 93:13304-13309.

Sandi C, Rose SPR, Patterson TA (1992) Unilateral hippocampal lesions prevent recall of a passive avoidance task in day-old chicks. Neurosci Lett 141:255-258.

Sherry DF, Jacobs LF, Gaulin SJC (1992) Spatial memory and adaptive specialisation of the hippocampus. Trends Neurosci 15:298-303.

Showers MJC (1982) Telencephalon of birds. In: Comparative correlative neuroanatomy of the vertebrate telencephalon (Crosby EC, Schitzlein HN, eds), pp 218-246. New York: Macmillan.

Squire LR (1987) Memory and brain. New York: Oxford UP.
Tonegawa S (1995) Mammalian learning and memory studied by gene targeting. Ann NY Acad Sci 758:213-217.

Veeman CL, Albin RL, Richfield EK, Reiner A (1994) Distribution of $\mathrm{GABA}_{\mathrm{A}}, \mathrm{GABA}_{\mathrm{B}}$, and benzodiazepine receptors in the forebrain and midbrain of pigeons. J Comp Neurol 344:161-189.

Weinberger RP, Rostas JA (1988) Developmental changes in protein phosphorylation in chicken forebrain. II. Calmodulin stimulated phosphorylation. Brain Res 471:259-272.

Weisskopf MG, Castillo PE, Zalutsky RA, Nicoll RA (1994) Mediation of hippocampal mossy fiber long-term potentiation by cyclic AMP. Science 265:1878-1882.

Wieraszko A, Ball GF (1991) Long-term enhancement of synaptic responses in the songbird of the hippocampus. Brain Res 538:102-106.

Wieraszko A, Ball GF (1993) Long-term potentiation in the avian hippocampus does not require activation of the $N$-methyl-D-aspartate (NMDA) receptor. Synapse 13:173-178.

Wojtowicz JM, Atwood HL (1988) Presynaptic long-term facilitation at the crayfish neuromuscular junction: voltage-dependent and iondependent phases. J Neurosci 8:4667-4674.

Zalutsky RA, Nicoll RA (1990) Comparison of two forms of long-term potentiation in single hippocampal neurons. Science 248:1619-1624.

Zucker RS (1989) Short term synaptic plasticity. Annu Rev Neurosci 12:13-31. 